\title{
Reuse principle for primary packaging circularity in the food system
}

\author{
Frøydis Sater ${ }^{1}$, Isaac Ortega Alvarado ${ }^{1}$, Ida Nilstad Pettersen ${ }^{1}$ \\ ${ }^{1}$ Norwegian University of Science and Technology (NTNU), Department of Design \\ froydsae@stud.ntnu.no \\ isaac.a.o.alvarado@ntnu.no
}

\begin{abstract}
Most of the plastic produced is only used once and is not recovered after its use phase, thus ending up as wasted material. Plastic in packaging is a challenging material. It accounts for a large amount of the plastic usage, and parts of it end up in nature after use, polluting masses of water and land. Furthermore its production contributes to greenhouse gas emissions. Plastic is however also one of the materials that contribute most to extending food shelf life and avoiding food waste. Packaging in the food system accomplishes several functions, but the benefits of the current system are also undermined by the linearity with which materials are approached. Opportunities to address the challenges posed by plastics may be found within the principles of a circular economy. The overall goal of this article is to explore how the circular economy reuse principle can transform the mainstream food system in order to reduce plastic waste from primary packaging. This paper reviews literature about the current mainstream food system, the functions fulfilled by food packaging, business models and design strategies relevant for the implementation of a circular economy based on reuse. It synthesizes existing knowledge that complements literature on the food and packaging systems through different reuse models. The discussion section suggests what a reuse system could entail, as well as its benefits and drawbacks. Reuse is presented as a plausible strategy to minimize waste and energy use by creating long-life products that can slow down the production of new material. This is a claim that can be tested empirically in further research in addition to testing other aspects such as logistics, consumer adoption and alternative ways of fulfilling the main functions of packaging.
\end{abstract}

Keywords: reuse, plastic packaging, waste reduction, food system, circular economy 


\section{Introduction}

Food production and post-production activities are responsible for $20-30 \%$ of the global human-made greenhouse gas emissions (Food Climate Research Network, 2018). Food postproduction activities such as packaging, transport, storage, processing, food preparation, waste disposal and management account for 5-10\% of these emissions. Discarded and mismanaged food packaging is also the cause of other undesired environmental impacts, such as land and water pollution, depletion of natural resources, solid waste, photochemical oxidation, and eutrophication (Varun et al., 2016). Despite the risks that discarded packaging poses, it fulfills functions that impact the whole food system.

Packaging in the food system covers three categories (Samanta et al., 2016). Tertiary packaging, such as plastic wrapping and wood boxes, is used to assist in transportation. Secondary packaging is the boxes produced to carry primary packaging to retailers. Secondary and tertiary packaging is used in high quantities and in homogenous materials, making them easier to collect, reuse and recycle. In contrast, the consumer brings primary packaging home and most of it ends up as mixed, contaminated and damaged materials after use, unfit for material recovery (Radhakrishnan, 2016).

Glass, metal, paper and plastic are common materials in primary food packaging (Kim et al., 2014), but plastic represents a major challenge. A larger relative amount is immediately discarded and cannot be recovered in the waste management system, as it is mixed with other materials and substances. On a global basis, $50 \%$ of the plastic produced is only used once and $40 \%$ of all plastic consumption is plastic packaging (Scarr \& Hernandez, 2019). In Norway, for example, only $32 \%$ of the plastic discarded from households goes to some sort of material recovery (Forum for sirkulær emballasje \& Emballasjeforeningen, 2019). Plastic packaging without proper management or recovery ends up returning to the environment. Plastic does not degrade in most natural conditions, but eventually degrades into micro plastics that can end up returning to the human food chain (Wetherbee et al., 2019). However, primary packaging made of plastic is used for protecting and containing food (Wohner et al., 2019). It lowers food waste, extends shelf life and is convenient for the user.

Sustainable alternatives to plastic may be found in transitioning to a circular economy. A circular economy approaches material challenges in production, use, and consumption by applying three principles: reduce, recycle and reuse (Dajian, 2008). This paper focuses on the application of the reuse principle, which is based on extending the use phase of existing products. For plastic packaging it could imply a reduction in production of new packaging and therefore in the amount of waste generated over a period of time.

The reuse principle is not normally adapted to primary packaging in the current mainstream food system. However, there are efforts to normalize its application in packaging solutions. The Ellen McArthur Foundation (2019a) has illustrated how circularity can be achieved through the reuse of packaging. Furthermore, existing research about packaging, food waste and environmental impacts of reuse and recycle materials (Butler, 2012; Radhakrishnan, 2016) can be coupled with design strategies to support reuse (Bocken, et al., 2016). Studies on packaging have primarily focused on the environmental impact of food packaging, improvement of current packaging or business models for a circular economy. This article seeks to connect these aspects as part of the sustainable transformations required for an upcoming circular economy. 
The article addresses the following research question: How can the reuse principle for a circular economy transform the mainstream food system to reduce material waste from primary packaging made of plastic? The research question is explored through a review of literature on the current food system, circular economy, reuse, and consumer behaviour.

\section{Literature Review}

The literature review in this article was conducted under a narrative overview approach (Cook et al., 1997; Juntunen, M. \& Lehenkari, 2019). Under this perspective, the article search was broad, and the selection was driven by the relevance to the topics in study. As a narrative overview, this article does not intend to present about a comprehensive overview of the reuse principle applied to packaging, instead, it aims at exploring the value of studying these topics together.

The articles selected were retrieved through the search engines Scopus, Google Scholar and Oria. The selection was purposive and not extensive as it had the objective of synthetizing some of the existing knowledge. The search terms included: "food packaging", "food system", "circular economy" and "reuse". The articles were selected based on their correlation with the search terms and the topics. The articles were mainly former research, but reports are included for statistical information about the problem. In addition, some news articles are included as sources of business examples. The selected articles were organized into three different categories: food packaging, circular economy and reuse, and consumer behaviour. Under the category of food packaging, only articles about plastics were reviewed, and the category of circular economy and reuse include examples about reuse business models that are not limited to food. Some articles were further explored to supplement with information and references from other works. Examples from the Norwegian context are used to elaborate on facts about packaging in a current food system.

\subsection{Food packaging}

Packaging fulfils a different purpose at each of the stages in the food system. The four main functions of packaging are protection, containment, convenience, and communication (Wohner et al., 2019). Protection avoids undesired physical, chemical, biological risks and product tamper (Yam \& Lee, 2012). The containment function prevents product loss and simplifies storage, transport, and distribution (Wohner et al., 2019). Containment is dependent on size, weight, form, and shape of the food. The right design will extend shelf life and reduce waste by prolonging usability (Marsh \& Bugusu, 2007). Further, convenience is vital to meet the needs of today's modern user (Wohner et al., 2019). It facilitates handling by designing the packaging to be easy-to-open, microwavable, or easy-to-empty. Lastly, communication facilitates brands and business strategy. In a competitive environment, special and innovative packaging can increase sales (Marsh \& Bugusu, 2007). It can also provide the user with details about cooking instructions, pricing, bar code, allergies, time-temperature indicator, ingredients, and nutritional content. For the supply chain it enhances distribution, retail checkout, and traceability. "Unless an emerging food packaging technology serves one or more of these functions, it is unlikely to be successful" (Yam \& Lee, 2012, p. 6).

Packaging for consumers varies with food market characteristics, and is developed to satisfy societal, economic, distribution-related, legal and technological requirements (Yam \& Lee, 2012). Consumer value and economy are driving forces for packaging development. Research and development activity is influenced by regulation, which for example is put in place to 
avoid food contamination. Developments in material science are further relevant to foodsafety and biosecurity issues, and to innovations related to the protective role of packaging. Lastly, ecology and environmental concerns motivate innovations in sustainable packaging.

Figure 1 illustrates the mainstream food system, based on overviews by Coles et al. (2003) and Accorsi et al. (2014). Materials for packaging are processed, stored, distributed, manufactured and end up in a packaging supply (Accorsi et al., 2014). Food is imported or transported from farmers, placed in storage and processed, before being transported for packaging and stored until distributed to food retailers (Coles et al., 2003). Finally, consumers buy the products, before the packaging is discarded (Coles et al., 2003). Afterwards, the packaging is recycled, reused, or incinerated. If the distances were shorter and waste production reduced, it would lower the cost and the environmental impact of the food supply chain (Radhakrishnan, 2016).

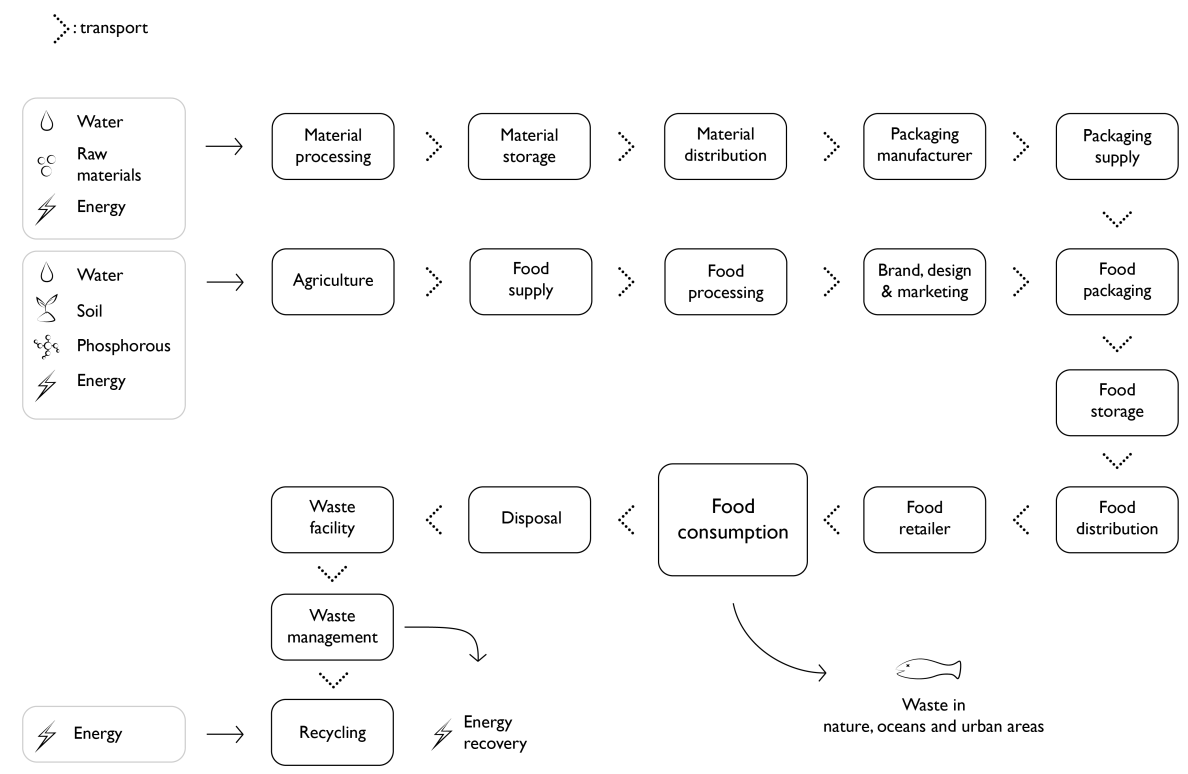

Figure 1. System map of the mainstream food system in the western world. Adapted from Accorsi et al. (2014, p. 90 ) and Coles et al. ( 2003, p. 6).

Plastic is a controversial material. It extends shelf life, is cheap to produce, has low density, and helps prevent the spread of bacteria during production, distribution and sales of products (Forum for sirkulær emballasje \& Emballasjeforeningen, 2019; Marsh \& Bugusu, 2007). On the other hand, it contributes to the spread of micro plastics. For example, 10,000 tons of micro plastics are emitted from Norwegian sources on land each year, and $50 \%$ ends up in the ocean (Miljødirektoratet, 2019). Norwegian households produce 78,915 tons of plastic waste each year (Grønn punkt, 2019). Micro plastics are everywhere, even in the rain (Wetherbee et al., 2019). According to a study done at the University of Bergen, plastic in the ocean is what concern Norwegians the most (Flydal, 2016). A study by Zimmermann et al. (2019) shows that there are toxic substances in some food packaging. In addition, plastic is made from oil, a non-renewable source (Rivera et al., 2018).

\subsection{Circular economy}

Our current food packaging system is based on linear economies. Materials are used and then thrown away (Ellen MacArthur Foundation, 2019b). This means that the system loses 
productivity, energy and natural resources (Jurgilevich et al., 2016). Unlike a linear system, a circular economy keeps materials in a use loop by applying three basic principles: reducing, reusing and recycling (Dajian, 2008).

The 'reduce' principle is based on lowering the amount of materials used in products and processes. Butler (2012) and Rivera et al. (2018) state that the environmental benefit of food packaging reduction is minimal for food with both high and low ecological footprints, due to the high emissions that come from food waste. In addition, the manufacturer can reduce the use of materials per product, but still produce a higher quantity of products that in the end are wasted (Yam \& Lee, 2012). For this reason, reducing the amount of packaging in one product has no impact on the speed of the resource flow (Bocken et al., 2016).

The 'recycle' principle constructs a circular flow of resources. From this perspective, materials are ideally returned to the manufacturer, broken down and incorporated into new products (Dajian, 2008). Recycling is valuable only if materials are recyclable. Globally, 14 $\%$ of the plastic is recycled, and $5 \%$ of the material cost is retained (Ellen MacArthur Foundation, 2017). Even though the collection of Norwegian plastic waste is much higher, the waste is shipped to Germany where it is either incinerated or recycled, depending on the quality (Amundsen, 2018). In today's market, it is cheaper to incinerate used plastic than to recycle it. In Norway, municipalities are responsible for collecting used plastic, but they are not capable of handling the amount of waste produced (Sykes, 2019). No actor is responsible for the whole system. Even though a lot of resources are put into collection of the plastic, the actual recycling rate is low.

The last principle is 'reuse'. In the circular economy context reuse encourages use of the product as much and as long as possible (Dajian, 2008). Reuse of plastic packaging can reduce the environmental impact of new plastic products because the necessary energy for processing virgin material is higher than the energy required for both recycling and reuse processes (Ross \& Evans, 2002). Reuse is one way to accomplish resource reduction, which is the same as waste prevention (Marsh \& Bugust, 2007). Resource reduction involves reusing materials and designing products to last longer.

According to Bocken et al. (2016), design strategies to create long-life products include design for attachment, trust, reliability and durability. They suggest that these are important in order to connect with the consumer and invent usable systems. The strategies for product-life extension are design for ease of maintenance, reparability, upgradability and adaptability, standardization, compatibility and dis- and reassembly (Bocken et al., 2016). Considering design strategies for product life extension in the implementation of reuse can be an opportunity for reducing material waste by keeping materials in the loop.

Above all, circularity in the food system means reducing both packaging and food waste (Jurgilevich et al., 2016). In contrast to this however, the report "Unwrapped" (Schweitzer et al., 2018) states that since 2005 food waste in European households has increased along with the amount of plastic waste. On the other hand, plastic play a crucial part in extending shelf life, thus packaging cannot be eliminated without a replacement that fulfils its current purposes. Inadequate preservation and protection, storage and transportation have been the major reasons for food waste (Marsh \& Bugusu, 2007). $30 \%$ of all food produced in the world becomes waste, resulting in high green gas emissions (Food Climate Research Network, 2018). Appropriate primary packaging can reduce this percentage. 


\subsection{Reuse models}

Rethinking how products are delivered to people is necessary in a circular economy (Ingilizian, et al., 2019), but doing so can also open up new business opportunities. Companies can earn money by creating new types of reusable packaging. If $20 \%$ of the plastic packaging is converted to reuse models, it will according to the Ellen MacArthur Foundation (2019b) not just reduce waste and pollution, but contribute to a USD 10 billion business market. The Ellen McArthur Foundation (2019b) argues that reusable packaging is necessary to reduce plastic pollution, and proposes four packaging reuse models:

- Refill the packaging from home (online service or a store).

- Refill the packaging on the go (dispensing point or a physical store).

- Return the packaging from home.

- Return the packaging on the go.

The first model, refill from home, is currently not used for food. However, several companies offer concentrated food products such as soups (cf. Toro, 2020) where water is added at home, saving transport-related emissions. An example of the second model, refill on the go, is Dasani PureFill water dispensers which make it possible for people to refill their own bottles with Dasani products from dispensing points (Wiener-Bronner, 2019). A company named Loop is an example of the third model, return the packaging from home. Their goal is to make reusable packaging mainstream through food home delivery services where they pick up and clean the reusable primary packaging (Sykes, 2019). In this model the firm Loop is responsible for the packaging. According to TerraCycle, the parent company, they reach parity with single use packaging after three life cycles. The last reuse model, return the packaging on the go, is similar to reverse vending. However, the reuse models provide cleaning and reuse of the bottles, while reverse vending is based on collection and recycling of bottles (Infinitum, 2019).

Reuse models tend to work best in local areas with high product volumes (Radhakrishnan, 2016). In the global food market, it is challenging to organize collection and disposal, as well as the cleaning, inspection and refill facilities necessary for reuse. Doing so requires management and coordination, and may be more expensive than producing and recycling single-use packaging (Twede \& Clarke, 2008; Sykes, 2019). However, circular business models can facilitate economically viable ways of reusing products through renewable materials (Bocken et al., 2016). The end-of-life can be determined at the design stage, based on environmental impact, quality and cost over time (Radhakrishnan, 2016). Standardization can contribute to efficiency, for example by enabling quick sorting and stacking of packaging (Twede \& Clarke, 2008). If the logistical cycle is minimized, costs may be lower than in the mainstream system (Twede \& Clarke, 2008). Furthermore, reuse does not necessarily influence food safety when considerations for cleaning are included at the design stage. Reuse may cause flavour carry-over during refill, but the chemical, physical and surface properties of the packaging are not influenced when packaging is reused (Jetten \& Kruijf, 2002).

\subsection{Consumers}

Changing a linear system means changing habits. Food choices often mirror people's identity, and consumers may feel that they have the right to buy whatever they want (Jurgilevich et al., 2016). The current food system has made it easy for people to buy products without concern for their origin or the environmental consequences of their disposal (Jurgilevich et al., 2016). 
In other words, the mainstream food system does not encourage sustainable ways of relating to food.

Reuse-based models exist in niche markets that compete with the mainstream system offerings. If they can change consumer's expectations, they may be able to challenge the mainstream system (Jurgilevich et al., 2016). To support adoption and normalization of such models, it can be useful to embed them in practices common to the mainstream service providers (Jurgilevich et al., 2016).

However, previous research on reuse of packaging shows that if consumers are aware of the environmental value of reuse it has a significant impact on their willingness to change unsustainable habits (Babader et al., 2016). Reuse behaviour is related to motivation, values and awareness. Laroche et al. (2001) argue that if consumers are exposed to green advertisement on packaging, it will increase the awareness and reassure consumers of the product's quality. In practice however, this is not as straightforward. Awareness and willingness do not necessarily translate into sustainable behaviours (Babader et al., 2016). From the perspective of the consumer reuse may also entail extra work, such astransporting, storing and cleaning food containers. This may be experienced as less convenient than simply sorting material waste to allow for recycling.

\section{Discussion}

To summarize, the article has reviewed literature on food packaging, circular economy, reuse models and consumer behaviour. The reviewed literature provides arguments to consider that applying the circular economy reuse principle may transform and require a transformation of the food system by removing some of the steps in the value chain. Design for reuse can help in leveraging the adoption of reuse among businesses that operate within the food system.

There has been relatively little recent research on how the reuse principle can transform the food system to reduce material waste. The Ellen McArthur Foundation (2019b) has illustrated reuse systems that can be complemented with the strategies offered by Bocken et al. (2016). Butler (2012) has studied the relation between food packaging and food waste, while Radhakrishnan (2016) has provided information about the environmental impacts of reuse and recycling. Several articles point to reuse as a preferable solution, due to less environmental impact than reduce and recycle strategies (e.g. Accorsi, 2014; Bakshi, 2019; Ellen MacArthur Foundation, 2019; Sykes, 2019). On the other hand, it may be difficult to implement reuse in the current global system because of challenges associated with logistics, economy and consumer adoption.

Figure 2 summarizes considerations relevant to implementing a reuse strategy in today's mainstream western food system. These considerations lead to principles for packaging design based on the four functions of packaging. In the future, if reuse were implemented, reduced packaging manufacturing frequency could be expected at the consumer product level, together with effects on other parts of the value chain, e.g. in processing, storage and distribution. Reuse would also require work on material usage in packaging design to support the physical conditions required for longer use, such as density and durability. Product life extension strategies such as the ones proposed by Bocken et al. (2016) could be applied to the containment function of the packaging design. Ease of maintenance, reparability, upgradability, adaptability, standardization, compatibility, and dis- and reassembly on the side 
of retailers could also lower costs by keeping containers in the loop. Consequently, this could reduce the environmental impacts by eliminating new resource extraction.

\section{Reuse considerations}

\begin{tabular}{|c|c|c|c|}
\hline Value chain & Authorities & Business model & Consumer \\
\hline $\begin{array}{l}\text { - Production } \\
\text { - Transportation } \\
\text { - Storage } \\
\text { - Reverse loop: } \\
\text { Collection } \\
\text { Cleaning } \\
\text { Inspection } \\
\text { Refilling }\end{array}$ & $\begin{array}{l}\text { - Cleaning policies } \\
\text { - Inspection policies } \\
\text { - Packaging design policies } \\
\text { - Development of new } \\
\text { technology } \\
\text { - Recommendation of } \\
\text { adoption } \\
\text { - Economical advantages } \\
\text { for businesses }\end{array}$ & $\begin{array}{l}\text { - Subscription } \\
\text { - Collaboration between } \\
\text { institutions and businesses } \\
\text { - Rent instead of buy } \\
\text { - Locality } \\
\text { - Reliability } \\
\text { - Easily adopted } \\
\text { - Costumer loyalty }\end{array}$ & $\begin{array}{l}\text { - Plan meals } \\
\text { - Organize food } \\
\text { - Clean packaging } \\
\text { - Take care of packaging } \\
\text { - Return packaging } \\
\text { - Motivation } \\
\text { - Awareness } \\
\text { - Values }\end{array}$ \\
\hline
\end{tabular}

\begin{tabular}{|l|l|l|l|}
\hline \multicolumn{1}{|c|}{ Protection } & \multicolumn{1}{|c|}{ Containment } & \multicolumn{1}{c|}{ Communication } & \multicolumn{1}{c|}{ Convenience } \\
\hline - Food safety & - Standardization & - Exchangeable information & - Ease of maintainance \\
- Product tamper & - Adaptability & - Digital communication & - Easy-to-open \\
- Quality & - Repairability & - Physical information & - Easy-to-empty \\
- Shelf life & - Upgradability & & - Easy-to-return \\
& - Density & & - Easy-to-clean \\
& - Durability & & - Easy-to-store \\
\hline
\end{tabular}

Figure 2. Principles to consider if the mainstream food system applies reuse for primary packaging.

At the food product level, reuse would most likely have no impact if appropriate measures for transport, cleaning and storage were implemented to maintain the food product's properties. Reuse alone will not transform the food we are consuming. However, the organisation of reuse services can make reuse more convenient. Keeping primary packaging at the local level may reduce some of the environmental impacts associated with global food markets and longdistance transportation for imported products. Reuse may also be introduced along with other system changes and food-related services, such as provision of local produce or as part of food subscription services.

When packaging reaches the consumption phase, the consumer is responsible for the product. Reuse-based models may require consumers to plan their meals, organize their food, and take care of and return the packaging to greater extents than what is the case in current mainstream systems. The reusable packaging would take up space and demand mental and physical effort from them. This may undeniably make reuse less convenient. Thus, it is a key challenge to ensure that the system is experienced as sufficiently convenient.

In the current food system, packaging is often treated as waste after one use. In a reuse system, there is a need for a reverse loop chain in the end-of-life, as shown in Figure 2. A standard way of designing the packaging would make the reverse loop more effective, as all products could be treated similarly. Ellen McArthur Foundation's four reuse models suggest different types of reverse loops. The models that suggest refill on the go or refill from home 
lower the cost for society and businesses. However, the model demands consumers to change habits. Return on the go or return from home are closer to the current system. The consumer brings the used packaging to a returning point or the packaging is picked up at home. Here, different models are imaginable. The municipality could for example be responsible for the maintenance and cleanliness of the packaging, but it might complicate logistics, lead to higher costs and add to the transport related emissions of the municipality.

A challenge with reuse systems is to maintain the main functions of packaging. They are necessary in the current system and will probably remain necessary in the future, in order to reduce food waste, ensure food safety, and enable communication within the supply chain and with consumers. Reuse systems can provide protective packaging, but reusable packaging should be designed differently. Research and development within material science is needed to ensure that the packaging appropriately can fulfil its protection- and health-related functions over time. Another technological aspect that might be necessary in a reuse system is innovation that makes cleaning and refilling of the packaging more efficient. Proper cleaning is essential for food safety, and should be considered as part of the packaging design process.

Economy is another reuse systems-related challenge. Resources, money and energy are needed to produce reusable packaging, refilling and cleaning posts, and systems may not be profitable. At the same time, reuse can reduce costs associated with waste management and transportation of recycled materials. Less plastic waste in Norway would for example mean reduction in transport of plastic waste to Germany. Furthermore, plastics are especially challenging to recycle, since it needs to be produced from pure material and cleaned by the consumer. Reuse will maintain existing materials in the loop and avoid extraction of raw ones, and this is in turn expected to reduce waste. However, changing current ways of acquiring food and managing waste represents a considerable challenge. It demands high and concerted efforts from governments, businesses and consumers in terms of regulations, investment and adoption. A more subtle strategy might be implementation of suggested packaging design principles in the current system, to improve the waste management and recycling rates. A holistic approach is anyway required when designing new food packaging routines, by including the public sector, businesses and consumers, who need to cooperate to improve the current system. Designers, politicians and businesses may apply circular models to reduce plastic waste, and policies can make it economically beneficial for businesses to invest in reusable packaging.

\section{Conclusion}

This study has provided an overview of the food packaging system and discussed possibilities for reuse to transform it. However, the review and discussion of articles on current food packaging, circularity, reuse models, and consumers does not make it possible to conclude on one specific path of action. The article has highlighted problematic issues related to the use of plastic packaging in today's linear economy, and shows that reuse could help keep existing materials in the loop and avoid extraction of raw ones. This might be a preferable solution to minimize waste, energy use, and achieve resource reduction by creating long-life products. Despite these positive observations, there are several challenges associated with reuse, such as logistics, consumer adoption and fulfilment of the four main functions of packaging. However, there is reason to believe that reuse should be applied where possible, accompanied by other circular solutions and measures aimed at facilitating adoption and changes in foodrelated practices. 
To further explore and conclude on the above-mentioned issues, more empirical research and evidence is needed. Such empirical evidence could be attained through projects concerning implementation of reuse in combination with design strategies. Future studies may also explore how design strategies applied in the development of reuse systems can achieve consumer adoption. Another suggestion for further research is to investigate how the reuse principle will affect everyday life and create change at the local level.

This paper has some limitations. First, few recent articles map the whole mainstream food system. A more updated and detailed study of the present system could give improved insight into resource and material use at each step. A recent review of reuse and packaging by Coelho et al. (2020) contributes in this direction. Furthermore, this article has focused on a limited number of studies on reuse, restricted to packaging. Even though the consumer perspective is somewhat included in the review, further research on consumer adoption would be useful in order to understand the implications of implementing reuse models. Further, quantitative assessments of greenhouse gas emissions and the amount of material waste that would be generated from reuse systems compared to the current system are needed in order to uncover whether reuse approaches indeed can lead to reduced environmental impacts, and whether they perform better compared to other packaging-related strategies, such as introduction of new bio based-materials.

\section{References}

Accorsi, R., Cascini, A., Cholette, S., Manzini, R., \& Mora, C. (2014). Economic and environmental assessment of reusable plastic containers: A food catering supply chain case study. International Journal of Production Economics, 152, 88-101. doi:10.1016/j.ijpe.2013.12.014

Amundsen, B. (2018). Hva skjer med plasten som kastes eller resirkuleres? Forskning. Retrieved from https://forskning.no/forurensning-miljo-plast/hva-skjer-med-plastsom-kastes-eller-resirkuleres/1207646

Babader, A., Ren, J., Jones, J. \& Wang, J. (2016). A system dynamics approach for enhancing social behaviours regarding the reuse of packaging. Expert Systems with Applications, 46, 417-425. doi:10.1016/j.eswa.2015.10.025

Bakshi, H. (2019). Plastic: friend, foe or frenemy? The Jakarta Post. Retreived from https://www.thejakartapost.com/academia/2019/08/29/plastic-friend-foe-orfrenemy.html

Beitzen-Heineke, E.F., Balta-Ozkan, N. \& Reefke, H. (2017). The prospects of zeropackaging grocery stores to improve the social and environmental impacts of the food supply chain. Journal of Cleaner Production, 140(3), 1528-1541.

Bocken, N. M. P., de Pauw, I., Bakker, C., \& van der Grinten, B. (2016). Product design and business model strategies for a circular economy. Journal of Industrial and Production Engineering, 33(5), 308-320. doi:10.1080/21681015.2016.1172124

Butler, P. (2012). Smarter packaging for consumer food waste reduction. Emerging Food Packaging Techniques, 409-434, doi:10.1533/9780857095664.4.409

Coelho, P. M., Corona, B., ten Klooster, R., \& Worrell, E. (2020). Sustainability of reusable packaging-Current situation and trends. Resources, Conservation \& Recycling: X, 6, 100037. https://doi.org/10.1016/j.rcrx.2020.100037

Coles, R., McDowell, D. \& Kirkwan. M. (2003). Food packaging technology (1st ed.). Oxford: Blackwell publishing Ltd. 
Cook, D. J., Mulrow, C. D., \& Haynes, R. B. (1997). Systematic reviews: synthesis of best evidence for clinical decisions. Annals of internal medicine, 126(5), 376-380.

Dajian, Z. (2008). Towards a closed-material loop. Chinese Journal of Population Resources and Environment, 2(1), 9-12. doi:10.1080/10042857.2004.10677342

Ellen McArthur Foundation (2017). The new plastics economy: Rethinking the future of plastics \& catalysing action. Retrieved from: https://www.ellenmacarthurfoundation.org/assets/downloads/publications/NPECHybrid_English_22-11-17_Digital.pdf

Ellen McArthur Foundation. (2019a). What is the circular economy. Retrieved from https://www.ellenmacarthurfoundation.org/

Ellen McArthur Foundation. (2019b). Reuse - rethinking packaging. Retrieved from https://www.ellenmacarthurfoundation.org/assets/downloads/Reuse.pdf

Feedback Global. (2015). Food waste in Kenya Feedback Global. Retrieved from https://feedbackglobal.org/wp-content/uploads/2015/07/Food-Waste-in-Kenya_reportby-Feedback.pdf

Forum for sirkulær emballasje \& Emballasjeforeningen. (2019). Veikart for sirkulær emballasje i Norge. Emballasjeforeningen. Retrieved from www.emballasjeforeningen.no.

Food Climate Research Network. (2018). Food systems and greenhouse gas emissions in Foodsource. Retrieved from https:/www.foodsource.org.uk/31-what-foodsystem $\% \mathrm{E} 2 \% 80 \% 99$ s-contribution-global-ghg-emissions-total

Flydal, E. F. (2016). Undersøkelse: plast i havet bekymrer nordmenn mest. VG. Retrieved from https://www.vg.no/

Grønn Punkt. (2019). Plastemballasje fra husholdninger. Grønn punkt. Retrieved from https:/www.grontpunkt.no/gjenvinning/plastemballasje-fra-husholdninger/

Infinitum. (2019). Om pantesystemet. Infinitum. Retrieved from https://infinitum.no/

Ingilizian, Z., Wingstrand, S. \& Lendal, A. (2019). Reusable packaging: 6 benefits beyond sustainability. Weforum. Retrieved from https://www.weforum.org/agenda/2019/07/reusable-plastic-packaging/

Jetten, J. \& de Kruijf, N. (2002). Quality and safety aspects of reusable plastic food packaging materials: influence of reuse on intrinsic properties. Food Additives Contaminants, 19(1), 76-88. doi: 10.1080/02652030110071309

Juntunen, M. \& Lehenkari, M. (2019) A narrative literature review process for an academic business research thesis, Studies in Higher Education, DOI: 10.1080/03075079.2019.1630813

Jurgilevich, A., Birge, T., Kentala-Lehtonen, J., Korhonen-Kurki, K., Petikäinen, J., Saikku, L., Schösler, H. (2016). Transition towards Circular Economy in the food system. Sustainability, 8(69), 1-14. doi:10.3390/su8010069

Kim, Y. T., Min, B., \& Won Kim, K. (2014). General Characteristics of Packaging Materials for Food System. Innovations in Food Packaging (2nd ed.), 13-35. doi: 10.1016/B9780-12-394601-0.00002-3

Laroche, M., Bergeron, J., \& Barbaro Forleo, G. (2001). Targeting consumers who are willing to pay more for environmentally friendly products. Journal of Consumer Marketing, 18(6), 503-520. https://doi.org/10.1108/EUM0000000006155

Marsh, K. \& Bugusu, B. (2007). Food Packaging-Roles, Materials, and Environmental Issues. Journal of food science, 72(3), 39-55. doi: 10.1111/j.1750-3841.2007.00301.x

Miljødirektoratet. (2019). Mikroplast. Retrieved from https://miljostatus.miljodirektoratet.no/

Rivera, X. Leadley, C., Potter, L .\& Azapagic, A. (2018). Aiding the Design of Innovative and Sustainable Food Packaging: Integrating Techno-Environmental and Circular 
Economy Criteria. Energy Procedia, 161(2019), 190-197. doi:https://doi.org/10.1016/j.egypro.2019.02.081

Radhakrishnan, S. (2016). Environmental Implications of Reuse and Recycling of Packaging. Environmental Footprints of Packaging, 165-192. doi:10.1007/978-981-287-913-4_7

Ross, S. \& Evans, D. (2003). The environmental effect of reusing and recycling plastic-based packaging system. Journal of Cleaner Production, 11(5), 561-571. doi: 10.1016/S0959-6526(02)00089-6

Samanta, K. K., Basak, S. \& Chattopadhyay, S. K. (2016). Potentials of Fibrous and Nonfibrous Materials in Biodegradable Packaging. Environmental Footprints of Packaging, 75-114. doi: 10.1007/978-981-287-913-4 4

Scarr, S. \& Hernandez, M. (2019). Drowning in plastic. Reuters. Retrieved from https://graphics.reuters.com/ENVIRONMENT-PLASTIC/0100B275155/index.html

Sykes, T. (2019). Recycle or reuse? Will Loop redefine the circular economy? Packaging Europe. Retrieved from https://packagingeurope.com/reuse-vs-recycle-loop-radicalvision-redefine-circular-economy/

Schweitzer, J. P., Gionfra, S., Pantzar, M., Mottershead, D., Watkins, E., Petsinaris, F., ten Brink, P., Ptak, E., Lacey, C., Janssens, C. (2018). Unwrapped: How Throwaway Plastic Is Failing to Solve Europe's Food Waste Problem (and What We Need to Do Instead). $\quad$ Retrieved from https://www.foeeurope.org/sites/default/files/materials_and_waste/2018/unwrapped_throwaway_plastic_failing_to_solve_europes_food_waste_problem.pdf

Toro. (2020). Lettere å velge klimasmart mat. Retrieved from https://www.toro.no/klodemerket/?gclid=CjwKCAjwkun1BRAIEiwA2mJRWQEw7R 1m9BRqQ5O4J-JC11U0GZc-WCAS370YEgz52wL3npa73eXv8xoC2EwQAvD_BwE

Trondheim kommune. (2018). Avfallsplan Trondheim kommune 2018-2030. Retrieved from https://www.trondheim.kommune.no/globalassets/10-bilder-og-filer/10-

byutvikling/kommunalteknikk/avfall/avfallsplan-for-trondheim-kommune-20182030.pdf

Twede, D. \& Clarke, R. (2004). Supply Chain Issues in Reusable Packaging. Journal of Marketing Channels, 12(1), 7-26. doi:10.1300/J049v12n01 02

Varun, Sharma, A. \& Nautiyal, H. (2016). Environmental impacts of packaging materials. Environmental footprints of packaging, 115-137. doi: 10.1007/978-981-287-913-4_5

Wetherbee, G., Baldwin, A. \& Ranville, J. (2019). It is raining plastic. U.S. Geological Survey Open-File Report 2019-1048, 1 sheet. doi:10.3133/ofr20191048.

Wiener-Bronner, D. (2019). Coca-Cola will sell Dasani in aluminium cans and bottles. CNN. Retrieved from https://edition.cnn.com/2019/08/13/business/coca-cola-dasanicans/index.html

Wohner, B., Pauer, E., Heinrich, V. \& Tacker, M. (2019) Packaging-related food losses and waste: an overview of drivers and issues, Sustainability 2019, 11(1), 1-15. doi:10.3390/su11010264.

Yam, K. \& Lee, D. (2012). Emerging food packaging technologies (2012). Woodhead Publishing Limited. doi:10.1533/9780857095664.1

Zimmermann, L. Dierkes, G., Ternes, T., Völker, C. \& Wagner, M. (2019). Benchmarking the in Vitro Toxicity and Chemical Composition of Plastic Consumer Products. Environmental Science \& Technology 2019, 53(19), 11467-11477. doi:10.1021/acs.est.9b02293. 